\title{
Submucosal esophageal hematoma following sclerotherapy: A rare complication
}

\author{
Ram Singh, YK Chawla, Upjeet Kaur, Neelam Malik, JB Dilawari
}

\begin{abstract}
A cirrhotic patient who developed an intramural hematoma of the esophagus as a complication of esophageal variceal sclerotherapy is reported. The hematoma resolved spontaneously within two weeks without any residual complications such as esophageal stricture. Can J Gastroenterol 1990;4(1):23-25
\end{abstract}

Key Words: Hematoma, Portal hypertension, Sclerotherapy

Hématome oesophagien sous-muqueux consécutif à une sclérothérapie: Une complication rare

RESUME: Un patient cirrhotique a développé un hématome intramural de l'oesophage, complication d'une sclérothérapie administrée dans le traitement des varices oesophagiennes. L'hématome s'est résolu spontanément en l'espace de deux semaines sans aucune complication résiduelle - sténose esophagienne, par exemple.

E NDOSCOPIC SCLEROTHERAPY IS NOW considered an important therapeutic modality in the management of variceal hemorrhages. There is now enough data to show that endoscopic sclerotherapy significantly reduces rebleeding risk (1-3); however, its effect on the survival of patients with cirrhosis is still controversial (2-4). Various complications of endoscopic sclerotherapy have been described in the literature $(5,6)$. This report deals with an extremely unusual complication.

Departments of Hepatology, Experimental Medicine and Radiodiagnosis, Postgraduate Institute of Medical Education and Research, Chandigarh-160012, India

Correspondence and reprints: Dr JB Dilawari, Associate Professor and Head, Department of Hepatology, Postgraduate Institute of Medical Education and Research, Chandigarh-160012, India Received for publication June 7, 1989. Accepted September 9, 1989

\section{CASE PRESENTATION}

A 55-year-old female presented in September 1986 with massive hematemesis and melena, which were diagnosed to be variceal in origin on endoscopy. She had normal liver function tests; however, a biopsy of the liver showed cirrhosis. After initial control of the bleed using a Sengstaken-Blakemore tube, the patient was started on endoscopic sclerotherapy (EST). EST was performed with $1 \%$ sodium tetradecyl sulphate at threeweek intervals using an Olympus fibrescope. The varices decreased in size from grade III to grade II after six sessions.

During the seventh session of sclerotherapy, one grade II varix was injected with $1 \mathrm{~mL}$ of the sclerosant. The patient did not complain of pain during or immediately after the procedure. Over the next $12 \mathrm{~h}$, however, she developed a progressive dysphagia to both solids and liquids including saliva, along with severe retrosternal pain.

On examination there was no hepatosplenomegaly and the lungs were clear. The patient had a normal coagulogram which was done soon after the complication occurred. 

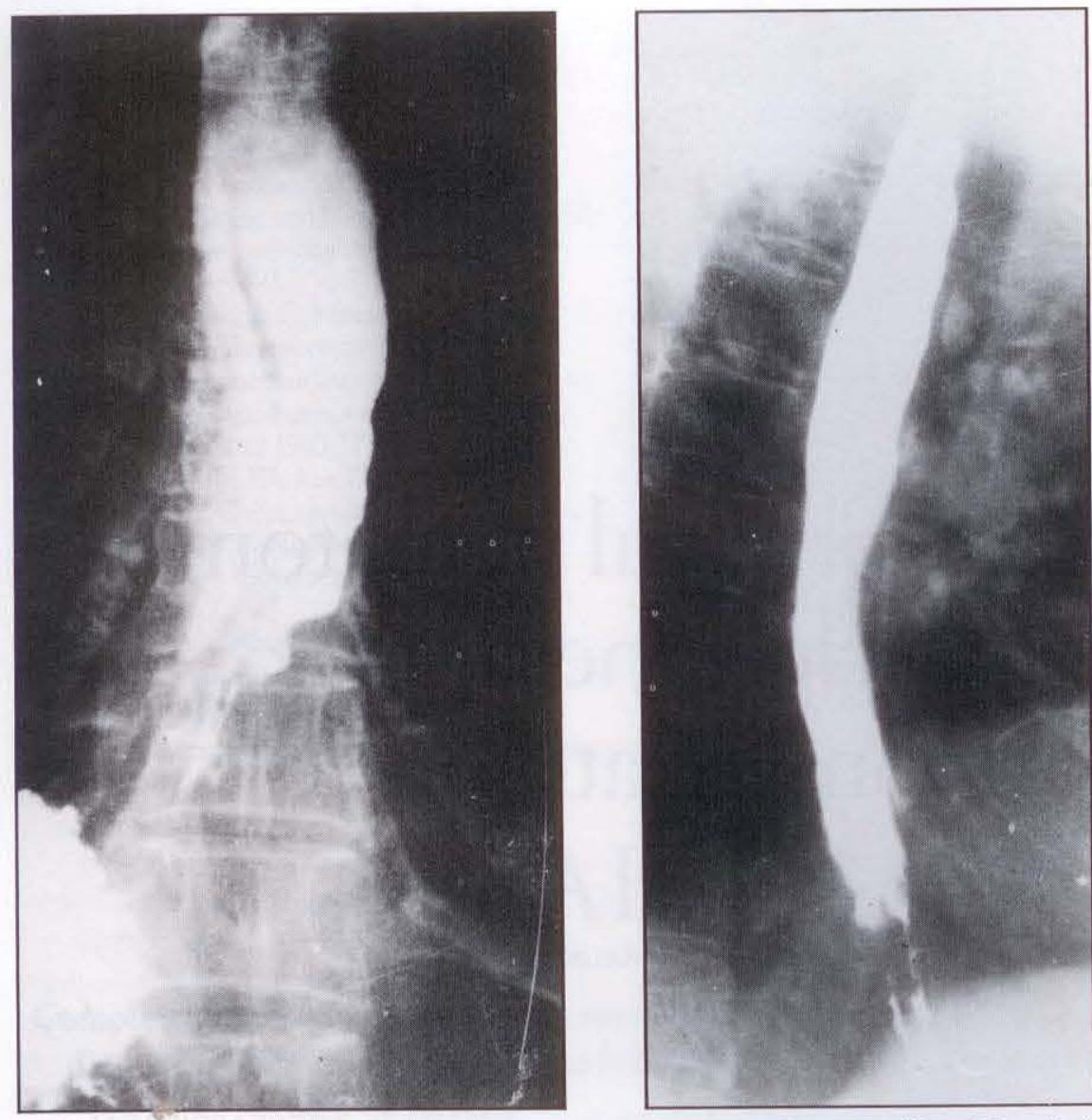

Figure 1) Left Barium swallow done the day after the complication, showing a filling defect which gives the esophagus the appearance of having a double lumen. Right Barium swallow showing a normal looking esophagus after two weeks of conservative therapy

An esophagogram with gastro conray (Conray 280; May \& Baker,India)(Figure 1) showed an apparent double lumen of the esophagus. There was no extramural leakage of the dye. Chest radiodiogram was normal. Upper gastrointestinal endoscopy revealed narrowing of the esophageal lumen $24 \mathrm{~cm}$ from the incisors with a dusky bluish nodular elevation completely occluding the lumen of the esophagus, suggestive of a submucosal hematoma. A computed tomography scan of the thorax revealed that the hematoma was confined to the submucosa of the esophagus, producing a double lumen effect (Figure 2).

The patient was kept nil by mouth and started on intravenous fluids. After $48 \mathrm{~h}$ she showed some improvement, being able to swallow liquids. After two weeks she could swallow solids without discom. fort. The patient remained afebrile over the two week symptomatic period. A repeat esophagogram after two weeks revealed a normal esophagus (Figure 1) while endoscopy showed an area of hyperemia at the site of hematoma extending from 24 to $32 \mathrm{~cm}$, without any narrowing of the lumen of the esophagus. A repeat computed tomography scan of the thorax confirmed the disappearance of the hematoma (Figure 2).

\section{DISCUSSION}

This case demonstrates a most unusual complication of sclerotherapy. The sudden and rapidly progressive dysphagia which developed within hours of EST, and the finding of a large dusky bluish submucosal lesion obstructing the lumen of the esophagus made hematoma a likely diagnosis, which was supported by a computed tomography scan.

Awareness of the occurrence of this hematoma as a complication of sclero-
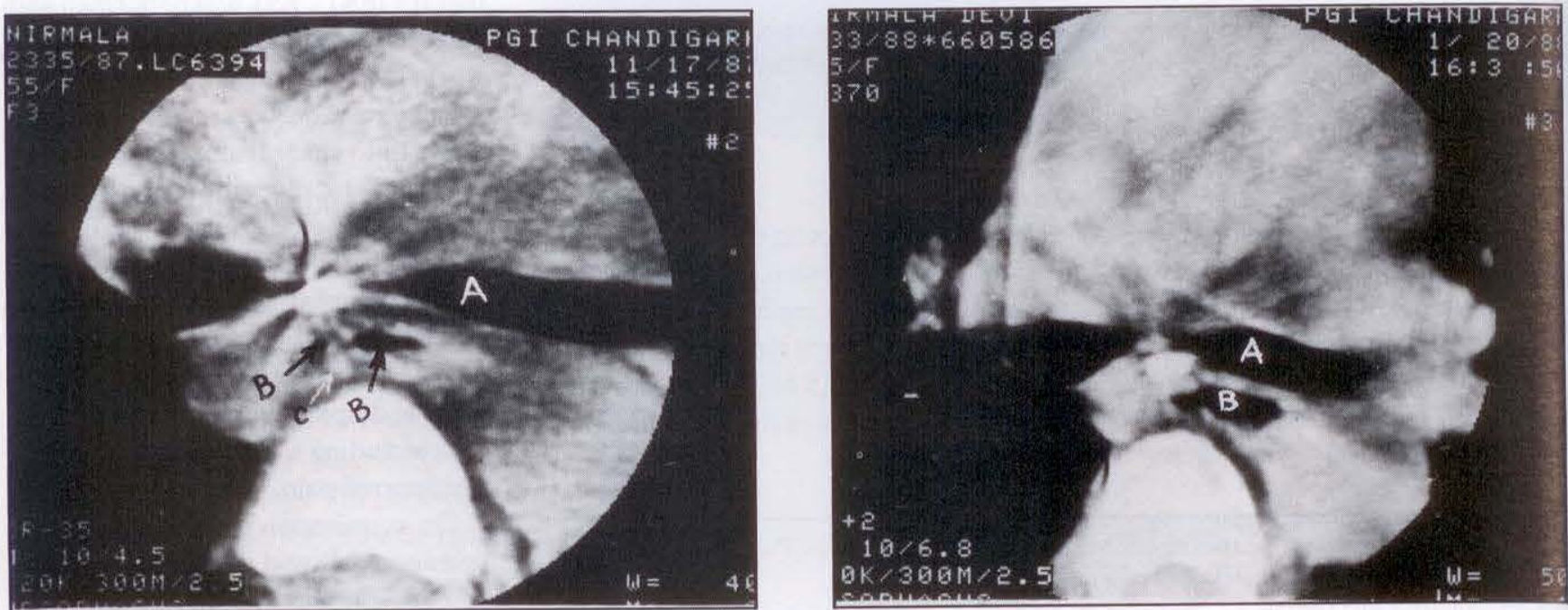

Figure 2) Left Computed tomography scan showing an intramural hematoma in the submucosa of the esophagus, producing a double lumen effect. Right Computed tomography scan showing the absence of hematoma after conservative treatment. A Bronchus; B Esophagus; C Hematoma 
therapy will aid in the recognition of this conditionaftersclerotherapy, presenting with a sudden onset of severe retrosternal pain and dysphagia. Similar symptoms have been previously reported $(6,7)$.

When an intravariceal injection is attempted using a free hand technique, some extravasation of the sclerosant into the surrounding tissues is inevitable (8).

\section{REFERENCES}

1. Clark AW, Westaby D, Silla DBA, et al. Prospective controlled trial of injection sclerotherapy in patients with cirrhosis and recent variceal haemorrhage. Lancet 1980;ii:552-4.

2. Korula J, Balart LA, Radvan G, et al. A prospective randomised controlled trial of chronic oesophageal variceal sclerotherapy. Hepatology 1985; 5:585-9.

3. Terblanche J, Bornman PC, Kahn D, et al. Failure of repeated injection sclerotherapy to improve long term survival after oesophageal variceal
Necrosis and hemorrhage into submucosal tissue from the submucosal vessels may have caused the hematoma following sclerotherapy.

Management of such lesions should be conservative, as is evident from this case study. Spontaneous resolution has been known to occur without any residual defects such as stricture or dysmotility.

bleeding. A five year prospective controlled clinical trial. Lancet 1983;ii:1328-32.

4. MacDougall BRD, Westaby D, Theodossi $A$, et al. Increased long term survival in variceal hemorrhage using injection sclerotherapy. Lancet 1982;ii: 124-7.

5. Galambos T. Endoscopic sclerotherapy. Ann Intern Med 1983:93:1009-11. (Edit)

6. Korula J. Pseudotumour of the esophagus. An unusual complication of esophageal variceal sclerotherapy. Am J Gastroenterol 1985;80:954-6.

7. Jones DB, Frost RA, Goodacre RL.
Intramural hematomas of the esophagus have also been described in the literature following protracted vomiting in the absence of preceding instrumentation $(9,10)$. Such hematomas usually occur in the distal esophagus following a MalloryWeiss laceration. Patients with impaired coagulation may also develop a hematoma without having vomited beforehand.

Intramural hematoma of the esophagus - A complication of endoscopic injection sclerotherapy. Gastrointest Endosc 1986;32:239-40.

8. Ayres SJ, Geoff JS, Warsen GH. Endoscopic sclerotherapy for bleeding esophageal varices: Effects and complications. Ann Intern Med 1983;98:900-3.

9. Kerr WF. Spontaneous intramural rupture and intramural hematoma of the esophagus. Thorax 1980;35:890-7.

10. Stevens S, Bernndson RA, Johnson LF. Esophageal hematoma. Four new cases. A review and proposed etiology. Dig Dis Sci 1981;26:1019-24. 


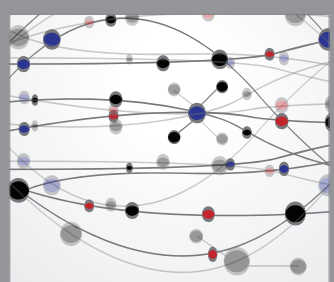

The Scientific World Journal
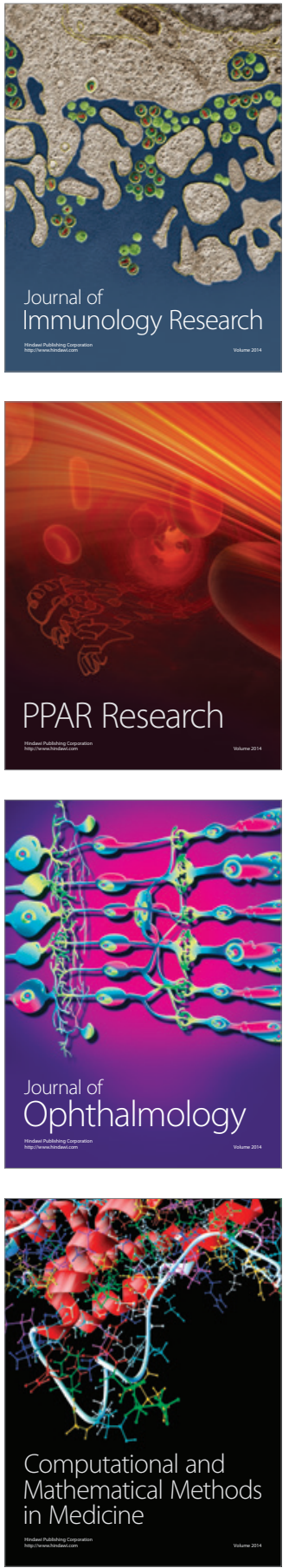

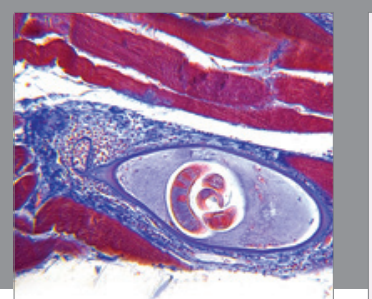

Gastroenterology Research and Practice

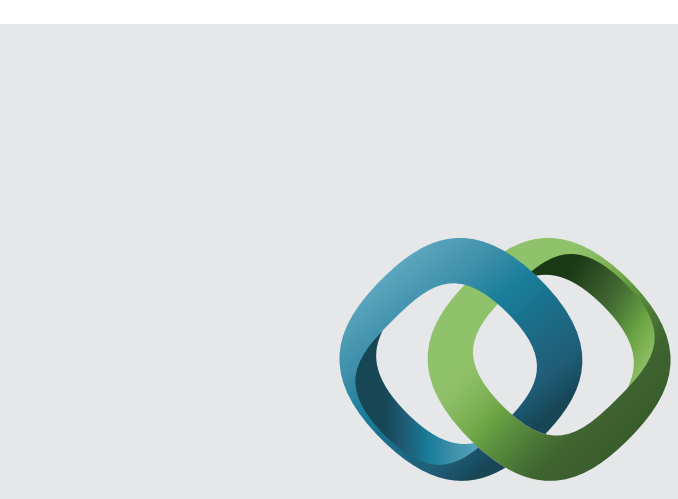

\section{Hindawi}

Submit your manuscripts at

http://www.hindawi.com
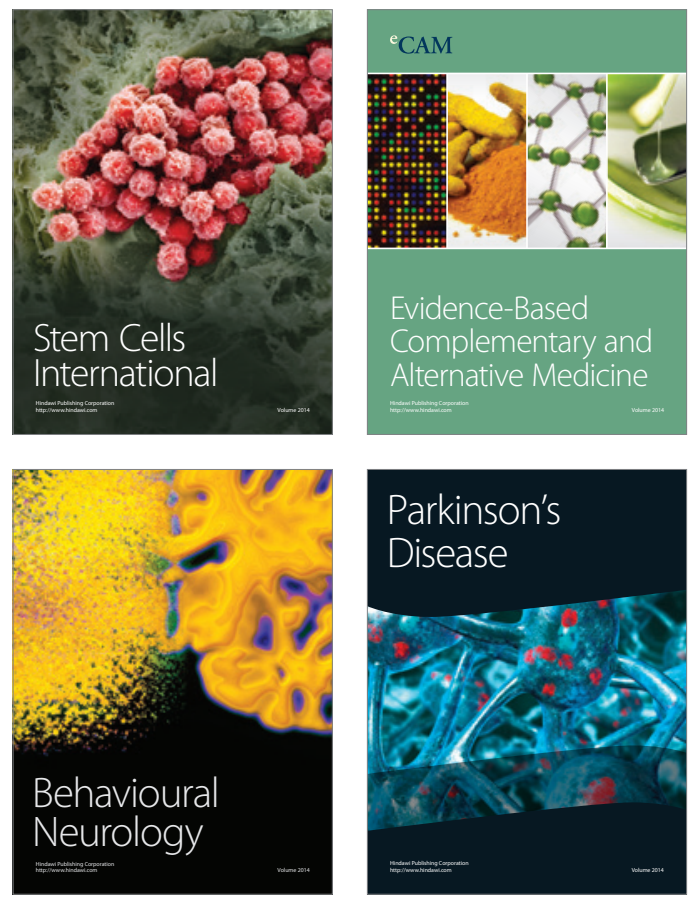
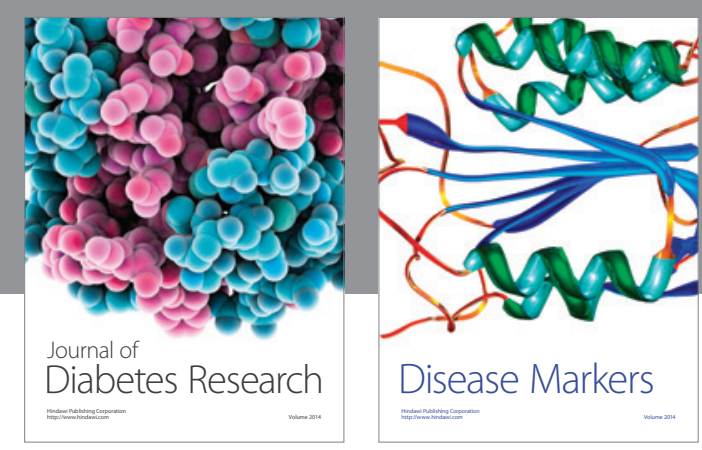

Disease Markers
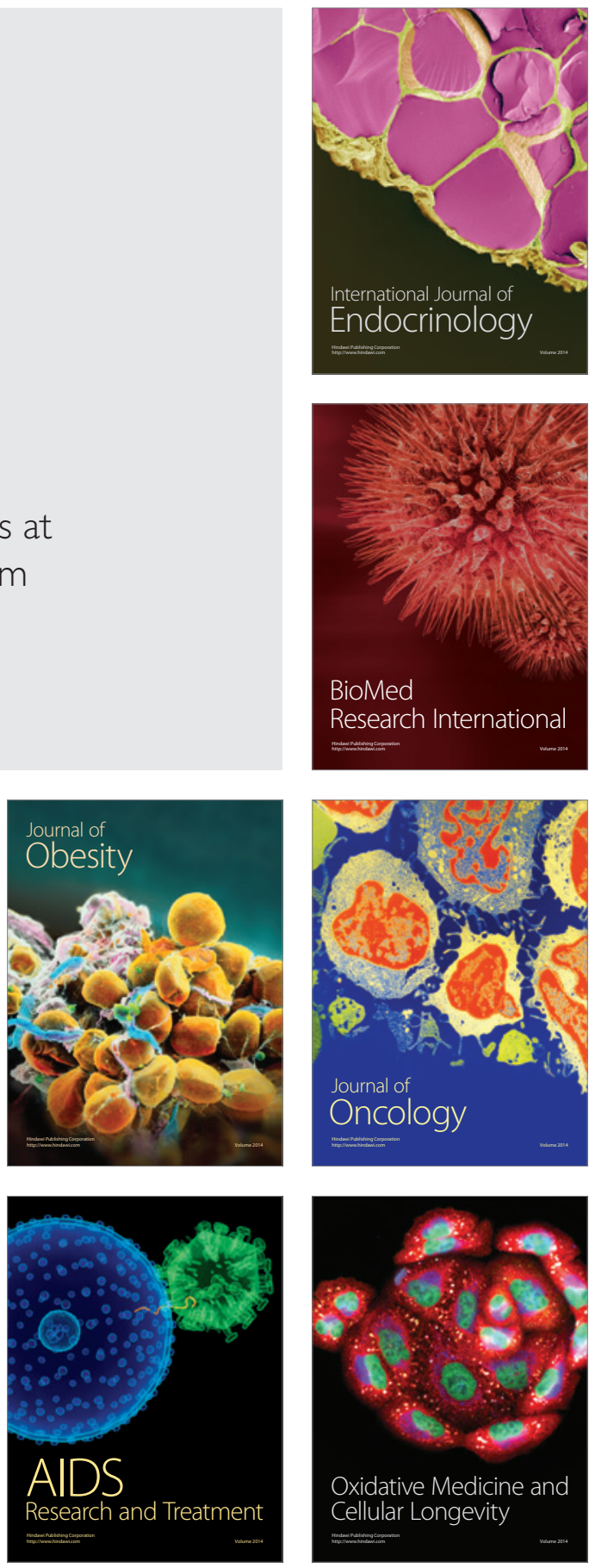